\title{
A IDENTIDADE DE GÊNERO NO INSTITUTO PENAL DE CAMPO GRANDE - MS
}

\author{
GENDER IDENTITY IN THE PENAL INSTITUTE OF CAMPO GRANDE - MS
}

\author{
Jamille Pesquero Deghaiche \\ Heitor Romero Marques ${ }^{\star \star}$ \\ Ana Cristina Rodrigues ${ }^{\star \star \star}$
}

\begin{abstract}
Resumo: $O$ presente trabalho aborda a realidade das pessoas LGBT, mais especificamente, as transexuais e travestis, em âmbito prisional, possuindo como foco, uma análise documental do Instituto Penal de Campo Grande - MS (IPCG). Frente a literatura relevante, a linha de pesquisa tenciona a função social do direito e interculturalidade, denominando-se como subáreas, os direitos sociais e políticas públicas. Foi realizada a análise doutrinária e bibliográfica, nas quais foram ponderados livros, relatórios governamentais, artigos científicos e monografias jurídicas, assim como foi apurada a legislação vigente. Ademais, a proposta consiste em proporcionar visibilidade a esta problemática, expondo as dificuldades, assim como os vários tipos de violência, as quais, os sujeitos supramencionados, transexuais e travestis são expostos. Isto posto, as implicações evidenciam desamparo para com a população carcerária em âmbito nacional, principalmente, com os transexuais que já se encontram em situação de vulnerabilidade. Tratandose do IPCG, o resultado foi satisfatório, contudo, apresenta determinados empecilhos, como a supressão na aplicação dos direitos para todos, sendo assim, somente os direitos mínimos como pessoa e transexuais, são respeitados.
\end{abstract}

Palavras-chave: Identidade de Gênero. Transexuais. Instituto Penal de Campo Grande - MS. Dignidade Humana.

Abstract: This work addresses the reality of LGBT people, specifically transsexuals and transvestites, in prison, focusing on a documentary analysis by the Campo Grande - MS Penal Institute (IPCG). It presents the social function of law and interculturality as a line of research, naming social rights and public policies as subareas, and has carried out a doctrinaire and bibliographical analysis, in which books, government reports, scientific articles and legal monographs have been studied, as well as the current legislation. The proposal is to give visibility to this problem, exposing the difficulties, as well as the various types of violence to which transsexuals and transvestites are exposed. That said, the implications show remarkable disrespect for the prison population nationwide and especially for transsexuals who are already in a vulnerable situation. In the case of the IPCG, the result was satisfactory, although it presents some impasses, the minimum rights as

\footnotetext{
Graduanda em Direito pela Universidade Católica Dom Bosco, UCDB, Brasil. E-mail: jamilledeghaiche@gmail.com.

* Doutorado em Desarrollo Local y Planificación Territorial, Mestre em Educação - formação de professores, Especialista em Filosofia e História da Educação, Bacharel em Pedagogia, Licenciado em Ciências Naturais.

*** Mestrado em Desenvolvimento Local pela Universidade Católica Dom Bosco, UCDB, Brasil. Professora na Universidade Católica Dom Bosco, UCDB, Brasil.. E-mail: profa.acmrodrigues@gmail.com.
} 
persons and transsexuals are respected.

Keywords: Gender identity. Transsexuals. Penal Institute of Campo Grande - MS. Human Dignity.

Recebido em: 25/03/2021. Aceito em: 27/04/2021. 


\section{INTRODUÇÃO}

A Lei de Execução Penal, dentre suas mais amplas atribuições, regulamenta a organização do Sistema Penitenciário Brasileiro, assim como objetiva punir, proporcionalmente, o condenado e humanizá-lo, buscando sua reintegração à sociedade por meio de medidas dispostas na referida lei, dever este atribuído ao Estado. Entretanto, a insuficiência do Poder Público em cumprir com sua obrigação, é visível, como consequência, possuímos um sistema carcerário deficiente, marcado pela superlotação, altos índices de reincidência e, gerador de mais violência, visto que, é conhecido por "escola do crime", na qual, escancaradamente, a Constituição Federal de 1988 e os Direitos Humanos são postergados, infringindo, assim, artigos imprescindíveis para uma vida humana digna.

A população carcerária, em decorrência do exposto, como um todo, está inserida nas minorias marginalizadas, minorias estas, consideradas infrutíferas para a sociedade, lançadas, então, à própria sorte, decorrente da indulgência do Estado. Considerando tal premissa, surgiu a necessidade de averiguar as condições de pessoas que são discriminadas incessantemente fora das grades, que são alvos de violências, preconceitos e discursos de ódio: a população LGBT, mais especificamente, as transexuais e travestis. A sigla LGBT, segundo o relatório governamental "LGBT nas prisões do Brasil" significa Lésbicas, Gays, Bissexuais, Travestis e Transexuais, "LGB" refere-se à orientação sexual e "T" à identidade de gênero, conceitos estes que serão melhores esclarecidos posteriormente.

Em consonância a relatórios bimestrais realizados pela Associação Nacional de Travestis e Transexuais (ANTRA), o Brasil é o país que mais mata mulheres transexuais e travestis, a nível mundial, salienta-se que não há qualquer meio oficial de controle do Estado sobre estes dados, evidenciando, o desamparo às comunidades em questão. Os números são apurados por defensores da causa, comprovando, assim, a subnotificação dos dados. Existem, aproximadamente, 809 mulheres trans e travestis em cárcere privado no Brasil, sendo, em sua maioria, condenadas por roubo e tráfico de drogas, presumindo-se que a causa, normalmente, está ligada à procura de "dinheiro fácil", consequência do preconceito que, geralmente, se inicia no seio familiar e permanece por toda a vida, perseguindo-as na fase escolar, fazendo-as largar os estudos, e por conseguinte, 
isto limita as chances no mercado de trabalho, considerando que já são muito escassas, restando-lhes como último recurso a prostituição ou a vida do crime.

Como será a (sobre)vivência de uma população, que fora das grades é vítima de diversos discursos de ódio, em um ambiente fragmentado e machista, em que não há garantias mínimas?

Neste contexto, este artigo tem como objetivo diagnosticar as políticas públicas existentes no âmbito do sistema prisional, dentre seus efeitos e aplicabilidade na vida das pessoas travestis e transexuais, expondo as dificuldades, assim como os vários tipos de violência a que são expostas, a física e a psicológica, a fim de produzir maior visibilidade a esta problemática. Em seguida, será abordada a identidade de gênero no Instituto Penal de Campo Grande, Mato Grosso do Sul.

Este estudo utiliza como linha de pesquisa, a função social do direito e interculturalidade, denominando-se como subáreas, os direitos sociais e políticas públicas, caracterizando a relevância de caráter social, em abordar a (in)visibilidade da problemática de gênero, e por tratar-se de uma questão atual e emergente na sociedade. A relevância de caráter jurídico caracteriza-se pela abordagem dos direitos, ou a escassez destes, para com as mulheres trans e travestis, no sistema carcerário. Foi realizada a análise doutrinária e bibliográfica, nas quais foram ponderados livros, relatórios governamentais, artigos científicos e monografias jurídicas, bem como, foi apurada a legislação vigente, que aborda o aludido tema.

Como fonte principal da pesquisa, foi utilizado o relatório encomendado pelo Governo Federal ao Ministério da Mulher, da Família e dos Direitos Humanos, "LGBT nas prisões do Brasil: diagnóstico dos procedimentos institucionais e experiências do encarceramento", publicado no presente ano de 2020, o qual objetivou averiguar a veracidade do cumprimento nacional da Resolução Conjunta no 1 de 15 de abril de 2014 (CONSELHO NACIONAL DE COMBATE À DISCRIMINAÇÃO, 2014), bem como, foram colhidos alguns depoimentos que, em sua maioria, mostraram a dura realidade vivenciada pelas mulheres em questão. Ademais, foi utilizado, também, o relatório produzido pela ANTRA "Assassinatos contra Travestis e Transexuais em 2020, Boletim n 02/2020", associação esta que a cada bimestre realiza levantamentos acerca de número e causas de morte de transexuais e travestis, sendo o citado relatório referente aos quatro primeiros meses do presente ano. 
Por fim, foi realizada a análise documental acerca do tratamento das pessoas transgêneras, e se a devida resolução conjunta está sendo respeitada no Instituto Penal de Campo Grande - MS. Para que este objetivo fosse alcançado, foi utilizado o documento "LGBT nas prisões do Brasil", o qual aponta o Instituto Penal como um dos estabelecimentos prisionais visitados durante as pesquisas.

Foi empregado, também como recurso de fonte de dados, a comunicação via e-mail com a Agência Estadual de Administração do Sistema Penitenciário (AGEPEN) de Mato Grosso do Sul, que disponibilizou um questionário para que a servidora do Instituto Penal respondesse, esta que foi a emissária das informações, salienta-se que como servidora pública, possui suas concepções ideológicas e a partir delas os dados foram examinados.

\section{A $O$ ATUAL SISTEMA PENITENCIÁRIO BRASILEIRO E A INCOMPATIBILIDADE COM A LEI DE EXECUÇÃO PENAL}

Antes de submergir à realidade do Sistema Penitenciário Brasileiro, faz-se necessário uma breve elucidação sobre a Lei de Execução Penal, conceituando-o, apresentando seu embasamento, sua finalidade, sua natureza jurídica, seu objeto, assim como a finalidade da pena.

A Lei o 7.210 , de 11 de julho de 1984 (BRASIL, 1984), conhecida como Lei de Execução Penal, possui, assim como todas as extensões do Direito, princípios constitucionais, que segundo Nucci (2018, p. 15), "não são princípios exclusivos da área, uma vez que são extraídos do Direito Penal e do Direito Processual Penal", contudo destaca-se alguns incisos elencados no Art. $5^{\circ}$ da Constituição Federal, dispositivo que é referência quando se trata de garantias fundamentais dos seres humanos, sendo: os incisos XLVI, que aborda sobre a individualização da pena; XLVII, que aponta quais penas não podem ser aplicadas em âmbito nacional, devido à desumanidade; XLVIII, que versa sobre o local correto para cumprimento de pena; XLIX, que garante aos presos, respeito à integridade física e moral, e por fim, o inciso $\mathrm{L}$, que assegura às presidiárias puérperas determinado período para amamentação.

Após a sentença penal condenatória ou sentença absolutória imprópria, parte-se para a execução, ou seja, o cumprimento da pena ou medida de segurança. A execução penal tem por finalidade, segundo dispõe a própria lei "efetivar as 
disposições de sentença ou decisão criminal e proporcionar condições para a harmônica integração social do condenado e do internado", melhor dizendo, segundo Marcão (2018, p. 30) "a execução deve objetivar a integração social do condenado ou do internado [...] segundo a qual a natureza retributiva da pena não busca apenas a prevenção, mas também a humanização", o autor conclui, então, que o objetivo é punir e humanizar.

A natureza jurídica da execução penal é ponto crucial de discussão, uma vez que há conflito de entendimento, no entanto a doutrina majoritária, entende que se trata de natureza jurisdicional. Durante o processo de execução, há atos que são próprios do juiz, isto é, atividades jurisdicionais, como também há atos administrativos, entretanto, caso ocorra conflito entre decisões administrativas e jurisdicionais, a última irá prevalecer.

Acompanhando o entendimento sobre a finalidade da pena, Nucci (2018), compreende que esta seja retributiva e preventiva. A prevenção consiste em reeducar e ressocializar o condenado, sendo este um dos principais objetivos da execução.

Seguindo o mesmo raciocínio, a finalidade preventiva apresenta dois aspectos: a geral, que subdivide-se em preventivo positivo e negativo, a primeira refere-se à reafirmar a existência do Direito Penal à sociedade; a segunda objetiva fortalecer o poder estatal. O segundo aspecto é o especial, subdividido, novamente, em preventivo positivo e negativo. O positivo é a (expectativa de) preparação do condenado para uma nova vida, pautando-se na reeducação e ressocialização da pena, como dispõe o Art. 22, Lei de Execução Penal (LEP); o negativo compreende intimidar o autor da infração penal para que não volte a cometer infrações.

Feitas as exposições iniciais em relação ao tema, inicia-se neste momento a questão principal do tópico: a realidade do atual do sistema penitenciário. O Brasil é - terceiro país com a maior população encarcerada no mundo, possui, aproximadamente, 773 mil encarcerados, entre presos provisórios e condenados, segundo dados coletados pelo Levantamento Nacional de Informações Penitenciárias (INFOPEN). A capacidade carcerária é de 461 mil vagas, de acordo com os mesmos dados, sendo assim, o sistema penitenciário sofre de superlotação, realidade decorrente de muitos fatores sociais, assim como é consequência de uma política criminal ineficaz e urgente. 
Além de números emergentes, é notório que o sistema prisional brasileiro se encontra em estado de calamidade, e situações indignas para a vida humana, não fazendo jus ao dispositivo constitucional, o qual assegura respeito à integridade física e moral do preso, Art. 5ํㅡ, XLIX, CF. O sistema carcerário, tem como objetivo a ressocialização do indivíduo, a educação e a devida punição proporcional ao delito cometido, dever este do Estado, previsto na LEP, que garante ainda a assistência material, jurídica, educacional, social, religiosa e à saúde (Art. 11, LEP).

Cabe aqui explanar ao que compreende cada assistência. A material engloba a alimentação, vestuário e instalações higiênicas. Já a saúde compreende o caráter preventivo e curativo, bem como atendimento médico, farmacêutico e odontológico. A jurídica é destinada aos presos e aos internados sem recursos financeiros para constituir advogado. A educação compreende a instrução escolar e a formação profissional do preso e do internado. O auxílio social tem por finalidade amparar o preso e o internado, e prepará-lo para o retorno à liberdade, e a religiosa promove um ambiente de fé, com liberdade de culto.

Marcão (2018, p. 54) relata de forma precisa que "o Estado só cumpre o que não se pode evitar". Ao concluir isto em sua obra, o autor se refere à assistência material, contudo, pode-se afirmar que o Estado só proporciona o trivial em todos os âmbitos em que é necessária a sua atuação, sobretudo quando se trata do sistema penitenciário. Todos estes auxílios estão previstos na referida LEP e são direitos dos apenados, entretanto, não é o que se verifica.

Conforme dispõe a Carta Magna, precisamente, Art. 5ํ, XLVI, a pena deve ser individualizada, este dispositivo é reforçado na LEP, uma vez que esta dispõe que deve haver a "classificação" dos presos, momento em que serão considerados os antecedentes e personalidade. Nucci $(2018$, p. 32$)$ conclui que o objetivo é "evitar o contato negativo entre reincidentes e primários, pessoas com elevadas penas e outros, com penas brandas, dentre outros fatores", este é um procedimento padrão, realizado com todos os presos. Diante da superlotação, torna-se de laboriosa execução apropriada, a "classificação", como vem em texto de lei.

Em consonância à Constituição, Art. 5ㅇ, XLIX, novamente, a LEP assegura o respeito à integridade física e moral dos presos, tal como é um direito garantido em tratados e convenções internacionais. É garantia dos encarcerados, igualmente, de acordo com o Art. 41 da LEP, exercício das atividades profissionais, intelectuais, 
artísticas e desportivas anteriores, proteção contra qualquer forma de sensacionalismo; igualdade de tratamento, salvo quanto às exigências da individualização da pena, entre outros.

Garantir, inteiramente, o que está disposto em lei, se os números de encarcerados correspondessem com sua capacidade, já seria um considerável obstáculo para o Estado. Nada se pode esperar quando os números ultrapassam de forma abrupta.

A falta de investimentos e a superlotação, que, consequentemente, desdobram-se em precariedade, rebelião, fuga dos presos, altos índices de reincidência, violência, falta de higiene e falta de medidas corretas para a devida ressocialização, além de várias outras situações únicas vivenciadas pelos encarcerados, geram o ciclo vicioso da "escola do crime", impondo dificuldades na contenção das consequências iminentes.

A Lei de Execução Penal, em teoria, traz uma forma humanizada da pena e sua vivência. Contudo, a realidade denota sua disparidade, para quem a acompanha. Não há tratamento digno, nem respeito à integridade física e moral, tampouco, atividades que diferenciam a rotina e igualdade entre os mesmos. Os direitos em questão, deveriam assistir a todos, de forma igualitária, sem que houvesse qualquer tipo de empecilho ou discriminação. Conquanto, não é o que ocorre nos presídios brasileiros, em especial, quando a questão é sobre identidade de gênero. $O$ encarcerado é discriminado. A encarcerada transexual é duplamente discriminada, sendo este o objeto desta pesquisa.

\section{A PROBLEMÁtICA DE GÊNERO E SUAS IMPLICAÇÕES NO SISTEMA PRISIONAL}

Anterior à discussão sobre os aspectos relacionados ao campo dos estudos de gênero e sexualidade, cabe situarmos a sua insurgência. Nesse sentido, abaixo, serão apresentados os conceitos de identidade de gênero e orientação sexual a partir da compreensão de teóricos no campo dos estudos feministas, que pensam e articulam a partir de leituras contemporâneas que ajudam a localizar a discussão, além da relação da diversidade sexo/gênero como sinônimos, mas a partir de sua desconstrução e performatividade.

Será abordada também a condição da população LGBT nos 
estabelecimentos prisionais em domínio nacional, tendo como objeto de investigação as mulheres transexuais e travestis no contexto do sistema prisional. Serão expostas as políticas públicas de proteção aos direitos LGBT's em âmbito internacional e nacional, que asseguram os direitos mínimos dentro das prisões, posteriormente, serão discutidas as recorrentes violações a esses direitos, salientando as violências físicas, psicológicas e sexuais, que as acometem, que são oriundas, em sua maioria, pelos outros encarcerados, como também pelos agentes penitenciários.

\subsection{Sexo e gênero: noções introdutórias}

O termo sexo expressa dentre seus mais variados significados, de acordo com o Dicionário Michaelis (2020), "conjunto de caracteres, estruturais e funcionais, segundo os quais um animal é classificado como macho ou fêmea. Conjunto de características anatomofisiológicas que distinguem o homem e a mulher: Sexo masculino; sexo feminino".

Do ponto de vista biológico, resumidamente, sexo é o que diferencia machos e fêmeas, através de genes situados em cromossomos, que intitulamos de homens e mulheres, e nesse sentido, a identidade de gênero surge como elemento promissor de análise das práticas, condutas e códigos sociais. Outro elemento de análise, circula no âmbito das práticas sexuais, isto é, no nível da orientação sexual e desejo, mas que não será foco de análise neste trabalho.

A identidade de gênero, nessa proposta é tomada como "um conceito essencialmente social, sendo sua construção e representação apresentada das mais diferentes formas, pelas diferentes culturas" (SOUZA; VIEIRA, 2015, p. 11), ou seja, assim como o conceito de sexo, o conceito de gênero também é construído social e culturalmente. A historiadora Scott (1995), em seus estudos, classifica gênero como uma percepção sobre as diferenças que há entre os sexos, influenciando aspectos culturais, históricos e sociais, criando, dessa forma, diversos padrões. Butler (2003, p. 25) em contrapartida, conceitua:

O gênero não deve ser meramente concebido como a inscrição cultural de significado num sexo previamente dado [...] tem de designar também o aparato mesmo de produção mediante o qual os próprios sexos são estabelecidos. 
Butler (2003) entende que a sociedade impõe coerência entre o sexo, o gênero e o desejo. O gênero está distante de qualquer acepção biológica. Concluise que esta já tem um pré-conceito estabelecido. No entendimento de Senkevics (2013) "o gênero aprisiona o sexo em uma natureza inalcançável à nossa crítica e desconstrução".

O termo, expressão de gênero, é como a pessoa se expressa. Orientação sexual relaciona-se à atração física, emocional e/ou amorosa de cada um, desdobram-se os seguintes termos: heterossexuais se relacionam com pessoas do sexo oposto; bissexuais se relacionam com ambos os sexos; gays são homens que se relacionam com outros homens e lésbicas são mulheres que se relacionam com outras mulheres.

Os termos supramencionados, relacionados à orientação sexual, independem da identidade de gênero da pessoa. Seguindo este raciocínio, Jesus (2012, p. 13) explana:

\footnotetext{
Uma pessoa transexual pode ser bissexual, heterossexual ou homossexual, dependendo do gênero que adota e do gênero com relação ao qual se atrai afetivosexualmente, portanto, mulheres transexuais que se atraem por homens são heterossexuais, tal como seus parceiros, homens transexuais que se atraem por mulheres também; já mulheres transexuais que se atraem por outras mulheres são homossexuais, e vice-versa.
}

Entende-se por identidade de gênero, a forma como a pessoa se vê, como se identifica, não possuindo, este conceito, relação alguma com sua orientação sexual. Vale ressaltar que, identidade de gênero não se relaciona aos órgãos genitais, mas à autoimagem, e nesse entendimento as pessoas são divididas em pessoas cisgênero e transgênero. Cisgênero é quando a pessoa se identifica com seu sexo designado em seu nascimento. As pessoas que não se identificam com sexo atribuído ao nascer, são chamadas de transgêneros, que podem ser transexuais, travestis, homens trans, mulheres trans e outras modalidades de expressão de subjetividade no que concerne a identidade de gênero.

Segundo o documento, "LGBT nas prisões do Brasil" (BRASIL, 2020a, p. 7), mulher transexual "é a pessoa do gênero feminino, embora tenha sido designada como pertencente ao sexo/gênero masculino ao nascer". Homem transexual (BRASIL, 2020a, p. 7) "é a pessoa do gênero masculino, embora tenha sido designada como pertencente ao sexo/gênero feminino ao nascer". A diferença entre mulher trans e travesti é quanto a aceitação de seu órgão genital, enquanto a 
primeira o rejeita, a segunda não sente desconforto.

\subsection{A identidade de gênero de mulheres transexuais e travestis no contexto dos presídios brasileiros}

Os direitos mínimos do ser humano encontram-se em estado de violação massiva, tratando-se de uma população carcerária de aproximadamente 773 mil presos (INFOPEN), deste número, pouco mais de 10 mil presos, são LGBT's declarados e destes, apenas 809 são travestis e mulheres trans (INFOPEN). Deste mesmo relatório, destaca-se uma circunstância preocupante: o estado do Amapá afirmou não ter identificado nenhuma pessoa LGBT em sua população prisional.

Partindo-se dessa premissa, é nítida a insegurança dos encarcerados em se autodeclararem LGBT's, deixando assim, os números comprometidos (BRASIL, 2020b). Não se trata de um medo frívolo, considerando o reflexo de uma sociedade machista e opressora, que usa violência como forma de intimidação e reprodução de valores do "patriarcado", que seguem enraizados, perpetuando até o atual momento. Consequentemente, o Brasil é o país que mais mata mulheres transexuais e travestis no mundo (ANTRA, 2020).

Tratando-se do primeiro quadrimestre do ano de 2020, correspondente aos meses de janeiro a abril, foram registrados 64 assassinatos de mulheres trans e travestis, representando um aumento de $48 \%$ relacionado ao mesmo período de anos anteriores (ANTRA, 2020). Ainda, neste mesmo período, foram registradas 22 tentativas de homicídio e 21 violações de Direitos Humanos (ANTRA, 2020).

É indispensável destacar, neste momento, a existência da política de subnotificação, que impede que os dados reflitam fielmente a realidade, uma vez que o Estado não possui qualquer meio oficial de controle destes dados, dificultando o levantamento de informações, seja por pesquisadores, associações, entre outros interessados que lutam pela causa.

Dentro das prisões a violência se potencializa, simplesmente pelo fato de refletir o que a sociedade produz, em um ambiente hostil e desagregador. O Ministério da Mulher, da Família e dos Direitos Humanos encomendou, neste ano, o relatório "LGBT nas prisões do Brasil: Diagnóstico dos procedimentos institucionais e experiências de encarceramento", tratando-se de um trabalho inédito, uma vez que buscou investigar sobre a real situação vivenciada por essas minorias, assim como 
verificar se os direitos por elas garantidos, são respeitados.

Foram visitados, ao menos, um presídio em cada estado e Distrito Federal. Através disto, foi possível constatar a violação de direitos básicos que compõem a identidade de gênero das transexuais e travestis como, por exemplo, a obrigatoriedade em cortar os cabelos longos, usar roupas masculinas, o não chamamento pelo nome social, falta de ala ou cela própria e a falta de acesso à hormonioterapia.

As mulheres trans e travestis ocupam uma situação de vulnerabilidade na sociedade, já que a discriminação, normalmente, se inicia no ambiente familiar, levando-as, na maioria das vezes, à procura da "vida fácil". Versando sobre o âmbito prisional, o abandono persiste, apenas $40 \%$ dos LGBT's possuem visitas cadastradas, consequentemente, estas não possuem meios de ter acesso à materiais que não são oferecidos pelos estabelecimentos prisionais, que são de meio externo da prisão, não lhes restando outras alternativas, a não ser a prostituição (BRASIL, 2020b).

\subsubsection{As políticas públicas de suporte às transexuais nas prisões}

Em 2006 foi publicado, Princípios de Yogyakarta, que objetiva a "aplicação da legislação internacional de direitos humanos em relação à orientação sexual e identidade de gênero" (PRINCÍPIOS, 2006, p. 1), sendo o Brasil signatário. Dentre seus 29 princípios, há o "direito a tratamento humano durante a detenção", que reitera a humanidade e respeito à dignidade da pessoa humana, assim como estabelece que a orientação sexual e identidade de gênero compõem a dignidade de cada ser humano (PRINCÍPIOS, 2006, p. 1).

Impõem aos estados, dentre as principais, obrigações de: evitar a marginalização determinada pela orientação sexual ou identidade de gênero; proporcionar o acesso adequado à saúde, atendendo às necessidades de tratamento de doenças sexuais, assim como os tratamentos hormonais e proteger os presos vulneráveis a qualquer tipo de abuso ou violência motivada pela orientação sexual ou identidade de gênero.

Tratando-se do âmbito nacional, há a Constituição Federal de 1988, que dentre seus objetivos fundamentais, busca "promover o bem de todos, sem 
preconceitos de origem, raça, sexo, cor, idade e quaisquer outras formas de discriminação" (BRASIL, 1988), ainda, em seu artigo $5^{\circ}$, referência em direitos fundamentais, há a garantia aos brasileiros e estrangeiros residentes no Brasil, de que "ninguém será submetido a tortura nem a tratamento desumano ou degradante", do mesmo modo que "é assegurado aos presos o respeito à integridade física e moral" (BRASIL, 1998).

Considerando tais incisos constitucionais, pode-se concluir que é dever do Estado, garantir que seja promovida a igualdade, tratamento humano e respeito entre os presos, independentemente, da identidade de gênero ou orientação sexual, bem como executá-las, segundo o princípio isonômico, que assegura tratamento igual aos iguais e desigual aos desiguais na medida de suas desigualdades, isto revela que as mulheres trans e travestis precisam de um olhar humanizado, uma vez que a identidade de gênero é construção, que requer resistência e persistência, que compõem, inclusive, o direito da personalidade.

Abordando o tratamento dos presos de forma específica, há a Lei de Execução Penal que reforça a garantia constitucional do respeito à integridade física e moral dos presos, entretanto, tal lei não traz de forma individualizada a questão de gênero, apenas seu artigo $3^{\circ}$ que explana "serão assegurados todos os direitos não atingidos pela sentença ou pela lei" (BRASIL, 1984), isto é, os direitos fundamentais continuam sendo aplicados aos seres humanos, mesmo privados de liberdade, visto que a pena não os transforma em objetos ( $\mathrm{NUCCl}, 2014)$.

Em 2014 foi publicada a Resolução Conjunta oo 1 pelo Conselho Nacional de Combate à Discriminação (CONSELHO NACIONAL DE COMBATE À DISCRIMINAÇÃO, 2014), resolução que teve papel fundamental e inigualável na proteção dos direitos aos LGBT's na prisão, em especial às mulheres trans e travestis, uma vez que tem como objetivo assegurar garantias específicas.

São direitos inerentes às transexuais e travestis: o chamamento pelo nome social; um espaço de vivência específico, em que se sintam seguros, para tanto, é necessária a manifestação de vontade expressa, uma vez que, em muitos lugares, isto é sinônimo de violência; a escolha de roupa, se femininas ou masculinas, assim como a opção de manter os cabelos longos; tratamento hormonal e visita íntima. Bem como é dever do Estado ter uma equipe capacitada para atendê-los a fim de que não se promova a discriminação. 
O Art. 4 desta resolução elucida que tanto as mulheres trans quanto os homens trans, devem ser transferidos para os presídios femininos, contudo, em 2019 foi julgada a Arguição de Descumprimento de Preceito Fundamental - ADPF oㅡ 527 (SUPREMO TRIBUNAL FEDERAL, 2018) em que a Associação Brasileira de Gays, Lésbicas, Bissexuais, Travesti, Transexuais e Intersexos - ABGLT afirmou que havia contradições na aplicação do referido Art. $4^{\stackrel{0}{ }}$, uma vez que pedidos judiciais e administrativos de transferência para presídios femininos eram negados metodicamente, pleiteando assim, que as mulheres trans cumprissem suas penas em presídios femininos, uma vez que tal artigo não era aplicado. O Ministro Barroso julgou favoravelmente, deferindo o pedido.

\subsubsection{A dupla penalização: a privação de liberdade e a violação aos direitos LGBT}

A resolução conjunta que garante os mínimos direitos aos LGBT's é uma orientação, isto é, aplicá-la por inteiro ou parcialmente, é uma decisão de cada estabelecimento prisional, uma vez que esta não impõe obrigatoriedade (BRASIL, 2020b). Dessa forma, uma característica preponderante decorrente do relatório (BRASIL, 2020b), foi a discrepância de protocolo e tratamento entre as unidades prisionais, decorrente da falta de comunicação entre as mesmas.

Cada estabelecimento prisional, externou meios únicos de procedimento e regulamentação. Entretanto, pressupõe-se que caso houvesse o compartilhamento de informações, de métodos que deram certo ou não, possivelmente, haveria diversas melhorias.

Dentre as principais violações que foram registradas, a falta de acesso à hormonioterapia é a mais recorrente, está prevista no Art. 7º, parágrafo único da Resolução. Dentre as unidades, são mínimas as que possuem o tratamento, caracterizando, assim, a violência psicológica, uma vez que, segundo relatos de uma travesti não identificada: "Quando eu me olho no espelho, eu não fico legal. [...] É complicado. A pessoa aqui entra em depressão por não se identificar com o corpo que se encontra" (BRASIL, 2020a, p. 84). A hormonioterapia é importante pois faz parte do processo de (trans)formação tanto corporal, como psicológica, que compõem a construção identitária das mulheres trans e travestis.

Do mesmo modo, faz parte desta construção o uso de cabelos longos, 
garantido no Art. 5o da Resolução, entretanto foi constatada em algumas unidades a obrigatoriedade em cortar os cabelos, com maior incidência nos estabelecimentos de triagem, juntamente com a violência e a proibição em usar roupas femininas, instituindo a violência física, uma vez que segundo o depoimento de uma detenta trans do Estado de Goiás, seu cabelo foi mutilado, já que ela e as outras foram forçadas a cortá-los, mesmo sendo asseguradas pela Resolução Conjunta (BRASIL, 2020a).

Quanto à disponibilidade de alas ou celas destinadas à população LGBT, disposto no Art. 3o da Resolução, destaca-se que 10 dos 26 estados, não a possuem, sendo eles: Santa Catarina, Acre, Rondônia, Roraima, Amapá, Tocantins, Amazonas, Rio Grande do Norte, Piauí e Rio de Janeiro (BRASIL, 2020a). Ponto que merece relevância, uma vez que (BRASIL, 2020a, p. 19):

Dispor de celas/alas para a custódia de LGBT não é uma garantia da anulação das violações de direitos às quais essa população está submetida, entretanto [...] a criação de celas/alas tem se mostrado uma tendência relativamente eficiente na redução mais imediata dessas vulnerabilidades.

Normalmente, nestes estabelecimentos, a população LGBT permanece nas celas de seguro, juntamente com os criminosos sexuais, idosos, deficientes, doentes, entre outros que varia entre as regiões (BRASIL, 2020a), ou seja, com os mais vulneráveis em âmbito prisional.

A falta de acesso aos preservativos é, novamente, ponto que merece destaque (BRASIL, 2020a, p. 84):

Manter pessoas LGBT no mesmo espaço e exigir deles que não haja relação sexual é tão irreal quanto esperar que homens e mulheres cisgênero heterossexuais, caso compartilhassem a mesma cela, também não mantivessem relações sexuais.

Como consequência desta política interna, que tem como objetivo evitar que usem os preservativos para outros fins (esconder drogas, aparelhos eletrônicos, entre outros), há a ocorrência de muitas doenças sexualmente transmissíveis, como relata uma detenta, que foi vítima desta omissão por parte do Estado (BRASIL, 2020a, p. 83): "Eu peguei uma doença porque eles não pagam preservativo aqui. A gente está sendo oprimido. [...] Dentro da cela eles não entregam preservativo. Eu, inclusive, tou pagando um castigo por conta de preservativo".

A atenção integral à saúde da população LGBT, está no Art. $7^{\circ}$ da Resolução, é possível identificar aqui a violência institucional, dado que é obrigação 
do sistema prisional garantir a segurança e o bom andamento da prisão, entretanto, é inadmissível que assegurem a segurança, sendo omissos em outros aspectos, colocando em risco a saúde de muitas pessoas, configurando aqui o nítido conflito entre saúde e segurança dos encarcerados.

A violência institucional é evidente também quanto à falta de especialização dos agentes penitenciários, capacitação que está prevista no Art. 10 da Resolução. Os relatos caracterizam fortemente o preconceito e a perseguição vivenciada pelas mulheres trans e travestis, tendo como autores os agentes penitenciários.

Uma mulher trans, não identificada, do estado de Minas Gerais relatou que em um dos dias de banho de sol, durante o procedimento, ela não levantou a blusa, abaixou apenas a calça e os agentes informaram que a mesma não iria, pois não tinha levantado a blusa. As outras trans que ouviram o fato, se adiantaram e tiraram a blusa e os agentes informaram que elas não iriam ao banho de sol, pois tinham tirado a blusa (BRASIL, 2020a). É evidente a discriminação, decorrente da identidade de gênero, assim como foi narrado pela mesma, que é muito comum os agentes proferirem palavras de baixo nível, como "desgraça, filho do capeta", entre outras (BRASIL, 2020a, p. 87).

Frisa-se, neste momento, que a narrativa não generaliza o comportamento dos agentes penitenciários em âmbito nacional, mas alerta sobre a existência de comportamentos que externalizam o ódio em pleno século XXI.

Os relatos de violência física e sexual são muito comuns, levando a danos psicológicos, que marcam para sempre a vida das vítimas, como evidenciam os relatos (BRASIL, 2020a, p. 52 e 63):

$\mathrm{Na}$ casa de pedra [triagem] me pegaram e rasparam meu cabelo e me colocaram em uma cela de homem. Eles me pegaram na força. A cela lá me botaram no meio de todo tipo de homem que tinha lá. Me tiraram a roupa e eu fiquei nua e depois me botaram em uma cela cheia de macho que eles pegaram. Os macho lá me pegaram tanto que pocou um caroço no meu ânus e eles me botaram pra cá que tem a cela de homossexual.

[...]

No [nome da unidade omitida] teve uma rebelião em 2015. 3 dias de rebelião. Aí um dos caras deu um pau em mim, me drogaram, me deram vários remédios. Daí eu fiquei na mão deles, eu fiquei refém deles. [...] Eles sempre querem dar um pau na gente, mas nesses momentos eles tem a oportunidade. [...] Aí eles me deram vários comprimidos e eu não tinha mais noção da situação. Eu só me dei de mim quando puxaram pra cortar meu cabelo. Foi aí que eu vi o que estava acontecendo. Daí me tiraram de lá, mas não levaram pro hospital nem nada. Eles sabiam que era um caso que ia dar muita polêmica. Abafaram, não me levaram para o hospital, não fizeram suturas no meu braço nem nada. 
Após o exposto, os relatos evidenciam que a privação de liberdade das mulheres trans e travestis nos estabelecimentos prisionais não é o único meio que elas "pagam" por seus erros. Além de estarem privadas de sua liberdade, são acometidas pela violação dos seus direitos e são vítimas de todo o tipo de violência, seja ela física, psicológica ou sexual que, consequentemente, produzem danos psicológicos irreversíveis, revelando o quão urgente e necessário é uma reforma estrutural e organizacional do sistema prisional brasileiro.

\section{A ANÁLISE DE IDENTIDADE DE GÊNERO NO INSTITUTO PENAL DE CAMPO GRANDE}

No estado de Mato Grosso do Sul, há mulheres trans e travestis em três unidades prisionais, sendo: o Instituto Penal de Campo Grande- IPCG, a Penitenciária Estadual de Dourados-PED e a Unidade Penal Ricardo Brandão UPRB em Ponta Porã. Tratando-se como lócus geográfico desta pesquisa, o Instituto Penal de Campo Grande, sendo este um estabelecimento prisional de regime fechado de segurança média que, em regra, é destinado a presos condenados, entretanto, há presos provisórios no estabelecimento aguardando os trâmites penais. Possui 400 vagas, mas conta com aproximadamente 1.500 encarcerados (BRASIL, 2020a), a superlotação é evidente.

O presídio é organizado em solares, cada solar possui 4 celas. A unidade conta com uma cela LGBT, que é localizada no primeiro solar e conta atualmente com 29 pessoas, deste número, 12 são mulheres trans ou travestis, os demais se declaram gays ou heterossexuais que são ou em algum momento foram parceiros das mulheres trans ou travestis, estes são chamados de "maridos".

Para que estes sejam transferidos para a cela LGBT, é necessário que se autodeclarem homossexuais mediante assinatura de um termo formal. Isto ocorre nos casos de homens gays ou héteros que se relacionam com mulheres trans e travestis. Porém, nos casos dos "maridos", normalmente, após irem para a cela LGBT, não retornam mais para suas celas de origem, mesmo após o término do relacionamento, uma vez que, a massa carcerária não os aceita de volta, evidenciando o preconceito existente com heterossexuais que se relacionam amorosamente com as transexuais, dado que, após assumirem tal relacionamento, 
são vistos, institucionalmente, como gays.

Ressalta-se que um homem cisgênero não deixa de ser hétero por se relacionar com mulheres trans ou travestis, posto que estas se identificam como mulheres, salientando, novamente, que identidade de gênero não possui relação linear com orientação sexual. Ao contrário, são dimensões que podem caminhar juntas, mas, novamente, não será o órgão genital que definirá as relações afetivas e sexuais, mas o entendimento das dimensões de gênero.

Em decorrência de tal medida institucional, que tem como objetivo "salvaguardar a administração prisional de quaisquer implicações administrativas" (BRASIL, 2020a, p. 40), acarreta na superlotação da cela LGBT, assim como "marca" o detento, visto que, a declaração de homossexualidade permanece em seu cadastro, mesmo se, por eventualidade, for detido novamente e até mesmo em outro estabelecimento prisional (BRASIL, 2020a).

O chamamento por nome social, além de estar previsto na Resolução Conjunta, é assegurado também no Decreto Estadual oㅜ 13.684, de 12 de julho de 2013 (MATO GROSSO DO SUL, 2013), que regulamenta que todos os órgãos públicos do Estado de Mato Grosso do Sul devem identificar travestis e transexuais pelo nome social. É um direito considerado inteligível, isto significa, fácil de ser respeitado, já que necessita de apenas uma ação subjetiva do indivíduo, entretanto, mesmo após seis anos de implementada a resolução conjunta, segundo relatos da servidora do Instituto Penal (2020), esta ainda é, notadamente, desrespeitada por alguns poucos agentes penitenciários, que apresentam grande resistência em reconhecê-las socialmente como mulheres e, no cotidiano, utilizam o nome de registro. Quanto ao uso de cabelos longos e roupas femininas, foi informado que ambos são permitidos pela unidade prisional (DEGHAICHE, 2020).

A Subsecretaria de Políticas Públicas LGBT, do Estado de Mato Grosso do Sul, iniciou a mediação do tratamento de hormônios às mulheres trans e travestis do Instituto Penal, que seria oferecido pelo Ambulatório de Saúde de Travestis e Transexuais, do Hospital Universitário Maria Pedrossian, entretanto, por motivos de mudança de gestão, não houve continuação no tratamento, consequentemente, no dado momento, não são agraciadas por tal garantia (BRASIL, 2020a).

É assegurado às mulheres trans e travestis, a igualdade de condições e recursos oferecidos pelo presídio, não havendo distinção entre a massa carcerária e 
as ocupantes da cela LGBT.

De acordo com a percepção da servidora pública (DEGHAICHE, 2020), esta que possui contato direto com as "meninas", adjetivo usado para se referir às mulheres trans e travestis na unidade, o convívio entre elas é, consideravelmente, conturbado, ponderando que muitas são usuárias de drogas, decorrente disto, possuem muitas faltas disciplinares, acarretando-lhes sanções, estas que são previstas no Regimento Interno da unidade, como também, em alguns casos, dependendo do ilícito ocorrido, há o aumento de pena.

Em conformidade com o exposto pela servidora pública (DEGHAICHE, 2020), é possível analisar também, que muitas meninas são reincidentes e não ficam muito tempo em liberdade, logo voltam para o cárcere. Este fato nos remete a outra problemática: a ineficácia do Poder Público em reintegrar os presos à sociedade, especificamente, soma-se ao "peso" de ser mulher trans ou travesti. O obstáculo mencionado, potencializa as faltas de oportunidade, principalmente, por, em sua maioria, não possuírem suporte familiar ou social, que pudessem auxiliá-las a recomeçar a vida fora das grades.

Prosseguindo a abordagem pautada na Resolução Conjunta, especificamente, Art. $7^{\circ}$, que garante atenção integral à saúde, semanalmente, são garantidos às meninas o acesso a preservativos, particularidade atribuída ao Instituto Penal muito significativa, vez que exprime atenção e cuidado, preservando assim a saúde dos encarcerados e contendo a disseminação de doenças sexualmente transmissíveis, o que é frequente entre a população LGBT.

$O$ direito à transferência das mulheres trans e travestis para o presídio feminino, previsto no Art. $4^{\circ}$ da referida resolução, assim como a decisão cautelar dada pelo Ministro Luís Roberto Barroso do Supremo Tribunal Federal, na Arguição de Descumprimento de Preceito Fundamental, no 527, não é adotada nacionalmente, todavia, questionadas sobre remota possibilidade, a recusa é generalizada (SUPREMO TRIBUNAL FEDERAL, 2018), isso decorre do bom convívio que as detentas possuem com os encarcerados e, segundo a servidora (DEGHAICHE, 2020), o cotidiano é pacífico, sendo raros, praticamente escassos os momentos marcados pelo preconceito e desrespeito entre eles. Outro fator que incide nesta decisão, é a falta dos companheiros, assim como, segundo elas, o convívio entre muitas mulheres, geraria muitos conflitos (BRASIL, 2020a). 
Há relevância em apresentar o projeto de iniciativa da Subsecretaria de Políticas Públicas LGBT e do Centro de Referência em Direitos Humanos, Prevenção e Combate à Homofobia (CENTRHO), em parceria com a Agência Estadual de Administração do Sistema Penitenciário (AGEPEN), que promove palestras quinzenais, palestras e orientações que abordam sobre saúde, questões jurídicas, autoestima, cidadania, entre outros assuntos que objetivam informá-las sobre os meios de proteção e até mesmo tratamento de doenças sexuais, de tal modo, é feito o teste rápido de sífilis e HIV das detentas; questões jurídicas também são abordadas, a fim de cientificá-las sobre progressão de regime, faltas disciplinares, e outros temas que, normalmente, fazem parte do cotidiano destas.

É promovido também, a exibição de filmes educativos e atendimento psicossocial, conforme as necessidades das internas, isto é, percepções julgadas necessárias pela servidora, como por exemplo, buscar a melhoria no convívio entre elas. Estas e outras ações têm como finalidade trabalhar a autoestima e promover o respeito entre as mesmas, o que gerou como resultado uma evolução perceptível e muito proveitosa (DEGHAICHE, 2020).

Semelhante iniciativa implementada no referido estabelecimento prisional é a constelação familiar, prática terapêutica, ligada às ancestralidades, que possui como propósito identificar as causas dos problemas familiares e questões mal resolvidas entre gerações, e solucioná-las uma por vez, restabelecendo o equilíbrio familiar. Esta, como as outras ações são significativas para o desenvolvimento pessoal e social das presas, sendo o Instituto Penal de Campo Grande - MS uma das poucas unidades, dentre as examinadas em território nacional, no relatório "LGBT nas prisões do Brasil" (2020), que possui projetos e ações voltados para o público LGBT, revelando considerável solicitude para com as meninas.

As iniciativas expostas são feitas frequentemente, entretanto, no dado momento, devido à Pandemia da Covid-19, as atividades estão suspensas, mas, segundo a servidora do Instituto (2020), assim que possível, essas iniciativas retornarão.

\section{CONSIDERAÇÕES FINAIS}

Os estudos examinados apontam que o Sistema Penitenciário Brasileiro está 
comprometido desde a sua organização institucional à estrutural. A primeira é demonstrada pela falta de comunicação entre os presídios do Brasil, vez que não há padrão de tratamento algum com os encarcerados e, tampouco com as mulheres trans e travestis, isto decorre da não obrigatoriedade da referida resolução, juntamente com a nítida falta de preparo dos agentes penitenciários, que não passam por treinamentos e, em sua maioria, são tomados pelo comodismo do funcionalismo público, exercendo o mínimo de sua profissão, ações estas que possuem reflexo direto em todo funcionamento de um estabelecimento prisional, considerando que não possuem o olhar humanizado que o sistema demanda. $O$ comprometimento estrutural está ligado à superlotação, adversidade que acarreta a outros inúmeros problemas, que acumulados tornam-se irreversíveis, visto as proporcionalidades que tomam.

Decorrente do explanado, em 09 de setembro de 2015, foi julgado pelo Supremo Tribunal Federal, a Arguição de Descumprimento de Preceito Fundamental - ADPF 347, que declarou o estado de trâmites inconstitucionais no Sistema Penitenciário Nacional, isso exprime que a Corte Superior Brasileira tomou conhecimento da situação precária e reconheceu, o quão necessário e urgente é uma reforma, entretanto, cinco anos se passaram desde a mencionada declaração e nada fora feito. Portanto, entende-se que o sistema prisional não é, e está longe de ser uma prioridade para o Poder Público Brasileiro, visto que os devidos recursos necessários estão distantes de serem destinados a este setor.

Foi possível observar que a discussão sobre identidade de gênero, de modo geral, é emergente na sociedade, esta que ainda é considerada um "tabu", entretanto, trata-se de um tema evidente e relevante. Disto decorre uma considerável dificuldade dos que não conhecem completamente o tema, em entender conceitos e, principalmente, compreender a dura realidade $e$ as vulnerabilidades a que são expostas.

A identidade de gênero impõe ideia de desconstrução de padrões e estereótipos criados culturalmente, consequentemente, tudo o que está "fora dos padrões" da sociedade causa aversão, como ocorre com a população LGBT, em especial, as pessoas transgêneras, que compreende as mulheres trans e travestis, estas que são marcadas pelo preconceito por, praticamente, toda a vida, podendose concluir que a sociedade carrega parcelas dessa responsabilidade, pois é da 
intolerância que está disseminada que decorre diversas implicações.

Analisada a problemática de gênero em âmbito prisional, verificou-se que a Resolução Conjunta o 1 de 15 de abril de 2014 (CONSELHO NACIONAL DE COMBATE À DISCRIMINAÇÃO, 2014) é parcialmente aplicada nacionalmente, assim como há divergências em sua aplicabilidade em cada estabelecimento prisional, isto ocorre, pois, a mesma é apenas recomendada, não possuindo força de lei e não acarretando obrigatoriedade, pautando-se aqui a justificativa do não cumprimento de tudo o que nela é disposto. Diante deste cenário da administração dos presídios de "burlar" a resolução, é necessário que tais recomendações componham a legislação vigente, para que assim nenhum direito seja violado, como é recorrente atualmente.

Em tal contexto, foi possível concluir que na maioria dos presídios brasileiros, ainda há muita intolerância em aceitar e conviver com as mulheres trans e travestis, aversão esta que é demonstrada, inicialmente, pela própria instituição, quando direitos mínimos, como o chamamento por nome social, não são respeitados pelos agentes e, também pelos encarcerados, que percebem tal vulnerabilidade e se aproveitam de tal realidade, por exemplo, incentivam a prostituição no sistema prisional, gerando assim a objetificação do corpo trans.

De forma marcada, a violência psicológica e física, ter como responsável o Poder Público, é muito comum, vez que, são percebidas pela falta de tratamento de hormônios, "mutilação" dos cabelos longos, proibição de vestimentas femininas, falta de acesso a preservativos, não chamamento por nome social e a falta de alas/celas especificas.

Destas inúmeras violações à resolução conjunta, juntamente com a realidade do sistema prisional percebe-se a dupla penalização das mulheres trans e travestis, penas que as perseguem para além das grades, se considerarmos que 0 recomeço fora da realidade do crime é dificultoso, configurando, novamente, a deficiência do Estado em seu dever de ressocialização. Tratando-se do Instituto Penal de Campo Grande - MS, segundo análise documental e percepções da servidora já mencionada, foi possível concluir que o estabelecimento prisional cumpre parcialmente a resolução conjunta, já que direitos como chamamento por nome social, hormonioterapia e ala/cela específicos são desrespeitados. Assim como foi identificada a precariedade estrutural, decorrente da superlotação e a 
precariedade institucional configurada pelo despreparo dos agentes penitenciários.

As atividades desenvolvidas pela Subsecretaria LGBT, juntamente com o CENTRHO e AGEPEN, encontram-se suspensas devido a Pandemia de COVID-19, dessa forma não foram propostas atividades alternativas durante este período, somente uma palestra foi realizada no dia 28 de junho do presente ano, para a celebração do dia do Orgulho LGBT (AGEPEN). Vale ressaltar que as informações citadas são da perspectiva da servidora pública, não demonstrando fielmente a realidade vivenciada.

As (trans)formações, que envolvem tanto mudanças corporais e psicológicas, compõem a construção identitária das mulheres trans e travestis, sendo este um processo que demanda tempo, que é marcado inicialmente pela rejeição, sendo uma busca constante pela autoaceitação. O sistema penitenciário não é preparado para lidar com assuntos que demandam certa complexidade, ser mulher trans ou travesti no atual âmbito prisional, é ser resistência.

É emergente que este sistema se (trans)forme, não para que possa receber somente mulheres trans e travestis, mas para que possa receber todos os encarcerados de forma digna e humana, a fim de que sejam punidos e humanizados, e as leis sejam devidamente cumpridas e não componham apenas uma realidade utópica.

\section{REFERÊNCIAS}

ANTRA. Boletim no 02/2020: assassinatos contra travestis e transexuais em 2020. Antra, Rio de Janeiro, 2020. Disponível em: https://antrabrasil.files.wordpress.com/2020/05/boletim-2-2020-assassinatos-antra1.pdf. Acesso em: 15 ago. 2020.

BRASIL. [Constituição (1988)]. Constituição da República Federativa do Brasil de 1988. Brasília, DF: Presidência da República, 1988.

BRASIL. Lei no 7.210, de 11 de julho de 1984. Institui a Lei de Execução Penal. Brasília, DF: Presidência da República, 1984.

BRASIL. Levantamento Nacional de Informações Penitenciárias. Brasília, DF: Ministério da Justiça e Segurança Pública, 2020b. Disponível em: https://www.gov.br/depen/pt-br/sisdepen/mais-informacoes/relatorios-infopen. Acesso em: 13 ago. 2020.

BRASIL. LGBT nas prisões do Brasil: diagnóstico dos procedimentos institucionais e experiências de encarceramento. Brasília, DF: Ministério da Mulher, da Família e 
dos Direitos Humanos, 2020a. Disponível em: https://www.gov.br/mdh/ptbr/assuntos/noticias/2020-2/fevereiro/TratamentopenaldepessoasLGBT.pdf. Acesso em: 04 ago. 2020.

BUTLER, Judith P. Problemas de gênero: feminismo e subversão da identidade. Rio de Janeiro: Civilização Brasileira, 2003.

CONSELHO NACIONAL DE COMBATE À DISCRIMINAÇÃO. Resolução Conjunta no 1, de 15 de abril de 2014. Brasília, DF: CNPCP, 2014. Disponível em: https://www.gov.br/depen/pt-br/composicao/cnpcp/resolucoes/2014/resolucaoconjunta-no-1-de-15-de-abril-de-2014.pdf. Acesso em: 16 ago. 2020.

DEGHAICHE, Jamille Pesquero. [E-mail enviado a Agência Estadual de Administração do Sistema Penitenciário, MS]. Destinatário: Agência Estadual de Administração do Sistema Penitenciário, MS. Campo Grande, MS, 9 set. 2020. 1 email. Disponível em: jamilledeghaiche@gmail.com. Acesso em: 10 set. 2020.

JESUS, Jaqueline Gomes de. Orientações sobre identidade de gênero: conceitos e termos: guia técnico sobre pessoas transexuais, travestis e demais transgêneros, para formadores de opinião. Brasília, DF: [s. n.], 2012. Disponível em:

http://www.diversidadesexual.com.br/wp-content/uploads/2013/04/G\%C3\%8ANEROCONCEITOS-E-TERMOS.pdf. Acesso em: 21 ago. 2020.

MARCÃO, Renato. Curso de execução penal. 16. ed. São Paulo: Saraiva, 2018.

MATO GROSSO DO SUL. Decreto no 13.684 de 12 de julho de 2013. D determina a identificação pelo nome social de transexuais e travestis em órgãos públicos. Campo Grande. MS: Governo do Estado, 2013.

MICHAELIS. Dicionário Brasileiro da Língua Portuguesa. Michaelis, [s. I.], 2020. Disponível em: $\mathrm{http}: / /$ michaelis.uol.com.br/busca? $r=0 \& f=0 \& t=0 \& p a l a v r a=S E X O$. Acesso em: 20 ago. 2020.

NUCCl, Guilherme de Souza. Curso de execução penal. Rio de Janeiro: Forense, 2018.

$\mathrm{NUCCl}$, Guilherme de Souza. Leis penais e processuais penais comentadas. 8. ed. Rio de Janeiro: Forense, 2014. v. 2.

PRINCÍPIOS de yogyakarta: princípios sobre a aplicação da legislação internacional de direitos humanos em relação à orientação sexual e identidade de gênero. [S. I.: s. n.], 2006. Disponível em:

http://www.clam.org.br/uploads/conteudo/principios_de_yogyakarta.pdf. Acesso em: 15 ago. 2020.

SCOTT, Joan. Gênero: uma categoria útil para análise histórica. 2. ed. Recife: SOS Corpo, 1995.

SENKEVICS, Adriano. O conceito de gênero por Judith Butler: a questão da performatividade. Portal Geledés, [s. I.], 2013. Disponível em: 
https://www.geledes.org.br/o-conceito-de-genero-por-joan-scott-genero-enquantocategoria-de-analise/. Acesso em: 20 ago. 2020.

SOUZA, Mariana Barbosa de; VIEIRA, Otavio J. Zini. Identidade de gênero no sistema prisional brasileiro. In: SEMINÁRIO INTERNACIONAL DEMANDAS SOCIAIS E POLÍTICAS PÚBLICAS NA SOCIEDADE CONTEMPORÂNEA, 12., 2015, Santa Cruz do Sul. Anais [...]. Santa Cruz do Sul, RS: UNISC, 2015. Disponível em:

https://online.unisc.br/acadnet/anais/index.php/sidspp/article/viewFile/13222/2266. Acesso em: 13 jul. 2020.

SUPREMO TRIBUNAL FEDERAL. Ministro garante a presas transexuais direito a recolhimento em presídios femininos. Supremo Tribunal Federal, Brasília, DF, 2018. Disponível em:

http://www.stf.jus.br/portal/cms/verNoticiaDetalhe.asp?idConteudo=415208\&caixaBu sca=. Acesso em: 21 set. 2020. 